\title{
Regulation of the Enzymes of the meta-Cleavage Pathway of Pseudomonas putida: A Regulatory Model
}

\author{
By G. J. WIGMORE,* D. DI BERARDINO AND R. C. BAYLY \\ Department of Microbiology, Monash University Medical School, \\ Commercial Road, Prahran, 3I8I, Victoria, Australia
}

(Received 4 October 1976; revised 2 December 1976)

\section{SUMMAR Y}

Mutants of Pseudomonas putida NCIBIOOI5 were isolated which produced catechol 2,3-oxygenase and the subsequent enzymes of the meta-cleavage pathway constitutively, and were defective in phenol hydroxylase activity. All revertants of one mutant $\left(\mathrm{C}_{3}\right)$, and most revertants of a second mutant $\left(\mathrm{C}_{\mathrm{I}}\right)$, regained wildtype characteristics with respect to inducibility of phenol hydroxylase and the other meta-cleavage enzymes. Their behaviour was consistent with them being regulatory mutants.

Other mutants deficient in phenol hydroxylase activity were not constitutive for catechol 2,3-oxygenase and other enzymes of the pathway. Their properties were consistent with mutations in a structural gene.

A model in which phenol hydroxylase is under positive control and catechol 2,3-oxygenase and subsequent enzymes are under negative control is proposed for the regulation of enzymes of the meta-cleavage pathway in $P$. putida.

\section{INTRODUCTION}

Pseudomonas putida NCIBIOOI5 (strain U) grows at the expense of phenol and the isomers of cresol following meta-cleavage of catechol and the monomethylcatechols respectively. Wigmore \& Bayly (1977) suggested that all enzymes of the degradative sequence following the ring-cleavage enzyme are translated from a single polycistronic message. Hence these enzymes are part of a single regulatory unit or operon (Bayly, Wigmore \& McKenzie, 1977). There appears to be a single regulatory protein which mediates the expression of all genes for the catabolism of phenol and the isomers of cresol (Wigmore \& Bayly, 1974) and the effector molecule for the regulatory protein is the phenolic substrate (Feist \& Hegeman, 1969; Sala-Trepat, Murray \& Williams, 1972). However, the phenol hydroxylase is regulated separately from the other enzymes of the meta-cleavage pathway (Bayly et al., 1977). In this communication we report observations that support this proposal and suggest that the regulatory protein acts as both a positive and a negative control element.

\section{METHODS}

Enzyme assays. Catechol 2,3-oxygenase in cells grown on solid media was detected by spraying with Io mM-4-methylcatechol when the colonies became yellow. The hydroxylation of phenol and the isomers of cresol (collectively referred to as phenolic compounds) was measured manometrically as described by Bayly \& Wigmore (1973). 4-Oxalocrotonate

* Present address: Department of Biochemistry, School of Medicine, University of Miami, Florida, U.S.A. 
keto-enol tautomerase was assayed as described by Sala-Trepat \& Evans (197I) and 4-oxalocrotonate decarboxylase by the method of Wigmore \& Bayly ( I974). All other details are described in the preceding communication (Bayly et al., 1977).

Isolation of mutants. The parent strain and method of mutagenesis are described by Bayly et al. (1977). Mutants producing catechol 2,3-oxygenase constitutively were selected after diluting a mutagenized and expressed culture in phosphate buffer $\left(0.02 \mathrm{M}-\mathrm{KH}_{2} \mathrm{PO}_{4}\right.$, adjusted to $\mathrm{pH} 7 \cdot 4$ with $\mathrm{NaOH}$ ) to give 100 to 500 colonies per plate. This dilution was inoculated on basal medium containing fumarate and, after overnight incubation, the colonies were tested for the presence of catechol 2,3-oxygenase. Any isolate that produced catechol 2,3-oxygenase constitutively on three successive subcultures was selected for further study. About I000 to 2000 plates were inoculated initially for the isolation of one such mutant strain. Two mutants, PsUCI and PsUC3, were isolated from separate treatments with mutagen.

Spontaneous revertants of mutant $\mathrm{PsUC}_{3}$ were isolated after $48 \mathrm{~h}$ incubation on media containing either phenol or $o-, m$ - or $p$-cresol as sole carbon source at a frequency of about 400 revertants per $10^{9}$ cells plated. The frequency of isolation was independent of the carbon source used for selection. Spontaneous apparent revertants of mutant PsUCi were isolated after $48 \mathrm{~h}$ incubation on $o$ - or $m$-cresol at a frequency of approximately four revertants per $10^{9}$ cells plated. No revertants were obtained on either phenol or $p$-cresol.

Strains deficient in phenol hydroxylase were selected initially by their inability to grow on phenol by a technique of limited enrichment (Bayly \& Wigmore, 1973). Presumptive phenol hydroxylase-defective strains were selected as follows. About 50 strains unable to grow on phenol were incubated for $6 \mathrm{~h}$ in separate $250 \mathrm{ml}$ flasks containing $50 \mathrm{ml}$ fumarate basal medium plus phenol. Strains having at least both phenol hydroxylase and catechol 2,3-oxygenase would accumulate 2-hydroxymuconic semialdehyde, turning the medium yellow (Bayly \& Wigmore, 1973). 4-Methylcatechol (10 $\mu \mathrm{mol}$ ) was added to each colourless culture and within $\mathrm{I}$ to $2 \mathrm{~min}$, four of these cultures turned an intense yellow. These mutants were selected as presumptive phenol hydroxylase-deficient mutants and were designated PsU29, PsU30, PsU40 and PsU90: they are referred to collectively as the PsU29 series.

\section{RESULTS}

Constitutive production of catechol 2,3-oxygenase and subsequent enzymes of the meta-cleavage pathway

Mutants PsUCI and $\mathrm{PsUC}_{3}$ both produced high constitutive levels of catechol 2,3oxygenase on solid medium containing either fumarate, pyruvate, citrate or benzoate as sole source of carbon and also on nutrient agar. When acetate or succinate was used as sole carbon source the levels were much lower. The reduced level of catechol 2,3-oxygenase after growth on acetate is due to repression (Bayly et al., 1977), and succinate may have a similar effect. The high level of catechol 2,3-oxygenase produced on benzoate medium is of special interest since strain PsUo metabolizes benzoate exclusively via the ortho-cleavage pathway (Bayly \& Wigmore, 1973). It suggests that with mutants PsUCI and PsUC3 there is physiologically significant meta-cleavage of catechol formed from benzoate oxidation.

The enzymes of the meta-cleavage pathway acting later than catechol 2,3-oxygenase were also produced constitutively during growth on solid medium containing fumarate (Table I). The wild-type strain did not produce catechol 2,3-oxygenase unless phenol was present during growth. 
Table I. Activities of enzymes of the meta-cleavage pathway in extracts of PsUo and mutants $\mathrm{PsUCI}_{\mathrm{I}}$ and $\mathrm{PsUC}_{3}$

Activities were assayed in extracts prepared from organisms grown: (a) overnight on solid basal medium containing fumarate or fumarate plus phenol $(2.5 \mathrm{mM})$; and $(b)$ for $2 \mathrm{~h}$ after phenol $(2.5 \mathrm{~mm})$ was added to cells growing exponentially on fumarate. Enzymes were assayed as described in Methods and specific activities (except for tautomerase and decarboxylase) are expressed as nmol substrate used or product formed $\mathrm{min}^{-1}$ (mg protein) $)^{-1}$. Tautomerase activity is expressed as units of activity, where I unit represents the decrease of one absorbance unit at $295 \mathrm{~nm} \mathrm{~min} \mathrm{~m}^{-1}(\mathrm{mg}$ protein $)^{-1}$. Decarboxylase activity is expressed as: ++ , activity induced in the wild-type strain; , \pm 5 to $10 \%$ of the activity induced in the wild-type strain; -, no activity detected.

\begin{tabular}{|c|c|c|c|c|c|c|c|}
\hline \multirow[b]{2}{*}{ Enzyme } & \multirow[b]{2}{*}{ Phenol* } & \multicolumn{2}{|c|}{ PsUo } & \multicolumn{2}{|c|}{ PsUCI } & \multicolumn{2}{|c|}{$\mathrm{PsUC}_{3}$} \\
\hline & & (a) & (b) & (a) & (b) & (a) & (b) \\
\hline \multirow[t]{2}{*}{ 2,3-Oxygenase } & $\mathbf{P}$ & 100 & I 40 & I 40 & 510 & 100 & 100 \\
\hline & $\mathbf{A}$ & $<$ I & $<\mathrm{I}$ & 170 & $<\mathrm{I}$ & 90 & $<\mathrm{I}$ \\
\hline \multirow[t]{2}{*}{ Hydrolase } & $\mathbf{P}$ & 50 & 53 & 46 & I 2 & 45 & 36 \\
\hline & $\mathrm{A}$ & $<\mathrm{I}$ & $<\mathrm{I}$ & 27 & $<\mathrm{I}$ & 20 & $<\mathrm{I}$ \\
\hline \multirow[t]{2}{*}{ Dehydrogenase } & $\mathbf{P}$ & 20 & 19 & I & I & 20 & 13 \\
\hline & $\mathbf{A}$ & $<\mathrm{I}$ & $<\mathrm{I}$ & $<\mathrm{I}$ & $<\mathrm{I}$ & 19 & $<\mathrm{I}$ \\
\hline \multirow[t]{2}{*}{ Tautomerase } & $\mathbf{P}$ & $I \cdot I$ & I $\cdot 0$ & 0.90 & 0.87 & 0.69 & 0.65 \\
\hline & $\mathbf{A}$ & $<0.01$ & $<0.01$ & $0 \cdot 20$ & $<0.01$ & 0.58 & $<0.01$ \\
\hline \multirow[t]{2}{*}{ Decarboxylase } & $\mathbf{P}$ & ++ & ++ & ++ & ++ & ++ & ++ \\
\hline & A & - & - & - & - & + & - \\
\hline \multirow[t]{2}{*}{ Hydratase } & $\mathbf{P}$ & 380 & 730 & 1300 & 2500 & 520 & 500 \\
\hline & A & IO & $<$ IO & 380 & $<10$ & 450 & $<$ IO \\
\hline
\end{tabular}

* P, Phenol present during growth; A, phenol absent during growth.

\section{Constitutive synthesis of catechol 2,3-oxygenase is conditional}

Constitutive production of the enzymes of the meta-cleavage pathway by mutants $\mathrm{PsUCr}_{1}$ and $\mathrm{PsUC}_{3}$ occurred only after growth on solid media. In liquid media catechol 2,3-oxygenase and the subsequent enzymes of the meta-cleavage pathway were induced by phenol (Table I); the same pattern of enzymic activities was induced when an isomer of cresol was used. Production of the enzymes during growth of the organisms on solid media was not due to a compound present in the agar since no constitutive production was detected after growth of either mutant $\mathrm{PsUC}_{1}$ or mutant $\mathrm{PsUC}_{3}$ in liquid medium containing a layer of gelled agar in the bottom of the flask. Furthermore, mutants PsUCI and $\mathrm{PsUC}_{3}$ produced the enzymes constitutively when grown on medium solidified with Oxoid Ionagar or Oxoid agar no. 3 previously washed with 20 changes of distilled water.

The conditional expression of the phenotype of the mutants PsUCI and $\mathrm{PsUC}_{3}$ is similar to that of mutants of the PsULi2 series of regulatory mutants of PsUo previously described (Bayly et al., 1977). In both instances the phenotype on solid media is different from that observed in the wild-type strain.

\section{Absence of phenol hydroxylase in constitutive strains}

Neither mutant PsUCi nor PsUC 3 could use phenol or $o-, m$ - or $p$-cresol as sole carbon source. However, both mutants grew at a similar rate to the wild type in the presence of each of these phenolic compounds when an alternative carbon source such as fumarate was present, though the products of meta-cleavage did not accumulate. This behaviour differed from that of strain PsUo (Bayly \& Wigmore, 1973) and suggests, since catechol 2,3-oxygenase and subsequent enzymes were present, that phenol hydroxylase was absent. Mutants 
PsUCI and PsUC 3 exposed to phenol or $o-, m$ - or $p$-cresol for $20 \mathrm{~min}$ to $\mathrm{I} 5 \mathrm{~h}$ when growing in media containing either fumarate, acetate, citrate, pyruvate, succinate or in nutrient broth, lacked phenol hydroxylase activity but showed catechol 2,3-oxygenase activity. The behaviour was the same whether the organisms were grown in liquid media either with or without shaking or on solid media.

\section{Other phenol hydroxylase-deficient strains}

The behaviour of the four presumptive phenol hydroxylase-deficient mutants of the PsU29 series was consistent with a mutation in the structural gene of phenol hydroxylase and was similar to the phenol hydroxylase-deficient mutant described by Feist \& Hegeman (1969) and further studied by Sala-Trepat et al. (1972). Mutants of the PsU29 series could not use any of the phenolic compounds tested as sole source of carbon. Following induction with either phenol or an isomer of cresol, all meta-cleavage enzymes except phenol hydroxylase were present at wild-type levels.

The four mutants of the PsU29 series were not constitutive for catechol 2,3-oxygenase, as shown either by spraying fumarate-grown colonies with aqueous 4-methylcatechol or by assay of extracts of cells grown on the same solid medium. Therefore constitutive production of catechol 2,3-oxygenase in mutants $\mathrm{PsUCI}_{\mathrm{I}}$ and $\mathrm{PsUC}_{3}$ is not an obligatory consequence of loss of phenol hydroxylase activity and the genetic defect in mutants of the PsU29 series must be different from that of mutants $\mathrm{PsUC}_{1}$ and $\mathrm{PsUC}_{3}$.

\section{Revertants of mutants $\mathrm{PsUC}_{\mathrm{I}}$ and $\mathrm{PsUC}_{3}$}

Two hundred and seventy-one revertants of mutant $\mathrm{PsUC}_{3}$, selected randomly, all grew on media containing either fumarate, phenol or $o$-, $m$ - or $p$-cresol as sole carbon source. After growth on solid fumarate medium none of the revertants displayed constitutive catechol 2,3-oxygenase activity. Hence in mutant $\mathrm{PsUC}_{3}$ the same genetic defect probably resulted in constitutive production of catechol 2,3-oxygenase and subsequent enzymes of the pathway and inability to grow at the expense of any phenolic compound due to the absence of phenol hydroxylase.

Four hundred and thirty-two revertants of mutant PsUCI, isolated on $o$-cresol, grew like the wild-type strain on $o$ - or $m$-cresol but grew very poorly on phenol or $p$-cresol: on both phenol and $p$-cresol the medium turned yellow, which was consistent with the revertants having a defective dehydrogenase. These apparent revertants were similar to a partial revertant, PsU5/R2I, described by Bayly \& Wigmore (I973). A similar growth response was observed after inoculation of each of the apparent revertants into liquid basal medium containing a phenolic carbon source. These findings were consistent with the observation that mutant PsUCI had a defective dehydrogenase after induction with phenol (Table I). Approximately $40 \%$ of the apparent revertants of mutant PsUCI retained the ability to synthesize catechol 2,3-oxygenase constitutively on solid media. Assay of six of these revertants (selected on $o$-cresol) confirmed that they were still dehydrogenase-defective following induction with phenol. After 5 days incubation on $p$-cresol, 510 apparent revertants of mutant PsUCI were isolated. In all respects these strains behaved identically to the partial revertants selected on $o$-cresol and again almost $50 \%$ retained the ability to synthesize catechol 2,3-oxygenase constitutively on solid media. The slow growth rate of the apparent revertants on $p$-cresol is consistent with their being dehydrogenase-defective.

The partial revertants of mutant PsUCI which had regained phenol hydroxylase activity but which still produced catechol 2,3-oxygenase constitutively did not produce phenol hydroxylase constitutively. 


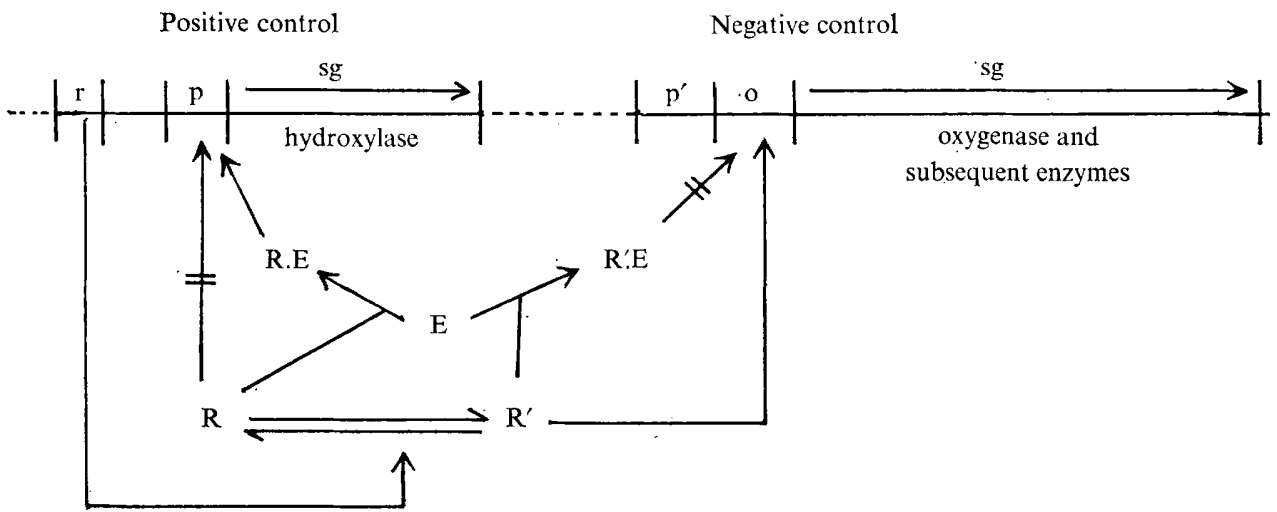

Fig. I. Proposed model for the regulation of the meta-cleavage pathway. R, Activator; $\mathbf{R}^{\prime}$, repressor; $\mathrm{E}$, effector; sg, structural genes; $r$, regulator gene; $p$, promoter of hydroxylase operon; $\mathrm{p}^{\prime}$, promoter of oxygenase and subsequent enzymes; o, operator.

\section{DISCUSSION}

It is difficult to reconcile the phenotype of mutant PsUCI with a single mutational defect. Since the lowered constitutive and inducible dehydrogenase levels of mutant PsUCi do not seem to be a consequence of the same defect that has resulted in concomitant constitutive synthesis of meta-cleavage enzymes and the absence of phenol hydroxylase, it is assumed that the defective dehydrogenase is a result of an independent lesion. Mutants of PsUo with a defective dehydrogenase as the only lesion in the meta-cleavage pathway have only been isolated as partial revertants and not as single mutations of the wild-type strain, even though a rigorous enrichment procedure (Wigmore, Bayly \& Di Berardino, 1974) was used.

The conditional nature of the constitutivity is not yet understood. Similar behaviour has been observed in two types of regulatory mutant so it is likely that a regulatory protein may be involved.

The concomitant loss of phenol hydroxylase and the constitutive synthesis of catechol 2,3-oxygenase and subsequent enzymes of the pathway appears to be due to a single mutational alteration of the genome, as all revertants of mutant $\mathrm{PsUC}_{3}$ and many partial revertants of mutant PsUCI regained wild-type character with respect to both changes. We have considered four alternative explanations to account for the phenotype of mutants PsUCI and PsUC3.

(I) A deletion mutation may have eliminated both the site of action of a repressor protein and also sufficient of the gene specifying the phenol hydroxylase for the protein to be no longer functional. This explanation is untenable because of the high reversion frequency of mutant $\mathrm{PsUC}_{3}$. It is also difficult to reconcile the conditional nature of the lesion in mutants PsUCi and $\mathrm{PsUC}_{3}$ with a deletion mutation.

(2) A system similar to that described by Cánovas, Ornston \& Stanier (1967) for mutants of Moraxella calcoaceticus could be involved. Here the constitutive synthesis of enzymes was not a consequence of a mutation affecting a regulatory gene, but resulted from the endogenous synthesis and accumulation of the inducer. For a similar system to account for the phenotype of mutants PsUCI and $\mathrm{PsUC}_{3}$ all phenol hydroxylase-defective strains should produce catechol 2,3-oxygenase constitutively. However, four phenol hydroxylase-defective mutants (of the PsU29 series) were not constitutive for catechol 2,3-oxygenase.

(3) The expression of the enzymes of the meta-cleavage pathway may be determined by a 
system of autoregulation in which the phenol hydroxylase enzyme would have both metabolic and regulatory roles. If the enzyme acts as a negative control element it should be possible to obtain mutants concomitantly phenol hydroxylase-deficient and constitutive for the remaining enzymes. Mutants of PsUCI and $\mathrm{PsUC}_{3}$ have these properties and, to act as a negative control element in this situation, phenol hydroxylase need exist in only one form. However, to act in the same manner in mutants of the PsU29 series phenol hydroxylase would need to exist in at least two forms (see reviews by Goldberger, 1974; Calhoun \& Hatfield, 1975).

(4) The lesion in mutants PsUCI and $\mathrm{PsUC}_{3}$ may affect the regulatory protein which could exist as both a positive control protein (activator), determining expression of the hydroxylase enzyme, and as a negative control protein (repressor) for the other structural genes (Fig. 1). The model assumes that the activator protein only serves to facilitate transcription of the hydroxylase gene in the presence of effector. Effective loss of this regulatory protein or its effector binding site would result in a phenol hydroxylase-deficient mutant.

The regulatory protein (possibly modified from the activator) also acts as a negative control (repressor) protein determining expression of catechol 2,3-oxygenase and subsequent enzymes of the meta-cleavage pathway. The repressor protein represses transcription only in the absence of effector. Loss of this regulatory protein or its operator binding site would result in the constitutive production of enzymes from those genes which are under the direct control of the repressor protein.

There are several systems described in which a regulatory protein in two different forms serves both as a positive and as a negative control element. In Escherichia coli two forms of a regulatory protein have distinct sites of action in determining transcription from the L-arabinose operon (see review by Englesberg \& Wilcox, I974). In the autoregulatory model for the regulation of isoleucine and valine biosynthesis, immature holo-threonine deaminase, together with charged transfer RNAs, serves to repress ilvADE and ilvB genes, whereas mature holo-threonine deaminase with either $\alpha$-acetolactate or $\alpha$-acetohydroxybutyrate promotes translation from the $i l v C$ gene (see review by Calhoun \& Hatfield, I975).

Without a system of genetic mapping in strain PsUo it is not possible to decide between possibilities (3) and (4), both of which require the regulatory protein to act at two sites and exist in two forms. The existence of such a regulatory protein would explain the noncoordinate repression of phenol hydroxylase and catechol 2,3-oxygenase by acetate, benzoate and 3- or 4-methylcatechol and the induction of catechol 2,3-oxygenase, but not phenol hydroxylase, by catechol (Bayly et al., 1977). It would also account for the properties of the partial revertants of mutant PsUCI which retained the ability to synthesize catechol 2,3-oxygenase constitutively without being constitutive for phenol hydroxylase.

The project was supported in part by grant no. D67/I6545 from the Australian Research Grants Commission. We thank M. Barbour for helpful discussions.

\section{REFERENCES}

Bayly, R. C. \& Wigmore, G. J. (1973). Metabolism of phenol and cresols by mutants of Pseudomonas putida. Journal of Bacteriology $\mathbf{1} 13$, I I $12-1$ I 20.

BAyLy, R. C., Wigmore, G. J. \& MCKenzie, D. I. (I977). Regulation of the enzymes of the meta-cleavage pathway of Pseudomonas putida: the regulon is composed of two operons. Journal of General Microbiology roo, 7I-79.

Calmoun, D. H. \& Hatfield, G. W. (1975). Autoregulation of gene expression. Annual Review of Microbiology 29, 275-299. 
Cánovas, J. L., Ornston, L. N. \& STANIER, R. Y. (I967). Evolutionary significance of metabolic control systems. Science 156, r695-I 699.

EnglesberG, E. \& Wilcox, G. (1974). Regulation. Positive control. Annual Review of Genetics 8, 2 I9-242.

Feist, C. F. \& Hegeman, G. D. (I969). Phenol and benzoate metabolism by Pseudomonas putida: regulation of tangential pathways. Journal of Bacteriology roo, 869-877.

Goldberger, R. F. (1974). Autogenous regulation of gene expression. Science 183, 810-816.

Sala-Trepat, J. M. \& Evans, W. C. (I97I). The meta-cleavage of catechol by Azotobacter species: 4-oxalocrotonate pathway. European Journal of Biochemistry 20, 400-4I3.

Sala-Trepat, J. M., Murray, K. \& Williams, P. A. (I972). The metabolic divergence in the meta-cleavage of catechols by Pseudomonas putida NCIB I00I5. Physiological significance and evolutionary implications. European Journal of Biochemistry 28, 347-356.

Wigmore, G. J. \& BAYly, R. C. (I974). A mutant of Pseudomonas putida with altered regulation of the enzymes for degradation of phenol and cresols. Biochemical and Biophysical Research Communications 6o, 48-55.

Wigmore, G. J. \& BAYLY, R. C. (I977). A partial order for genes determining enzymes of the meta-cleavage pathway in Pseudomonas putida. Journal of General Microbiology roo, 65-69.

Wigmore, G. J., Bayly, R. C. \& Di Berarino, D. (1974). Pseudomonas putida mutants defective in the metabolism of the products of meta-fission of catechol and its methyl analogues. Journal of Bacteriology I20, 3l-37. 